\title{
OBITUARY
}

\section{Sandy (Alexander) Pinkerton}

Spinal Cord (2011) 49, 322; doi:10.1038/sc.2010.135

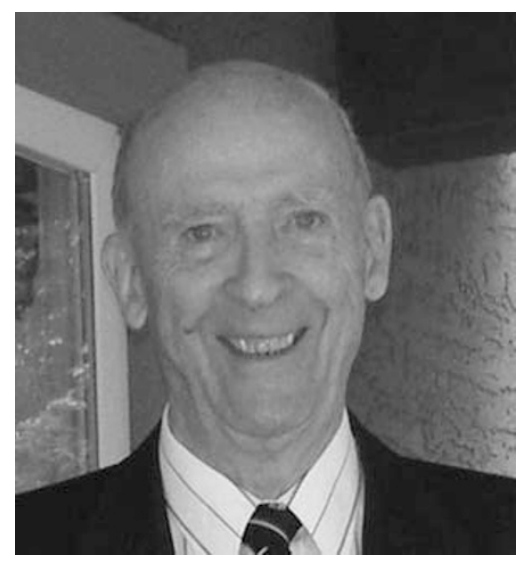

The ISCoS friends and colleagues of Sandy (Alexander) Pinkerton will be saddened to learn of his death on 20 January 2010 at age 86. Sandy joined IMSoP in 1963, was elected Emeritus in 1996 and a Fellow in 1998. He was on
Council from 1992 to 1999. Scottish born, Sandy obtained his degree in medicine at Glasgow University and was awarded a diploma in physical medicine by the Royal College of Physicians and Surgeons in London. He, Maisie and their two sons emigrated to Canada (a daughter was born there), where he joined the staff at Vancouver's GF Strong Rehabilitation Centre, becoming its medical director in 1954 and holding that position for 20 years. He became a Fellow of the Royal College of Physicians and Surgeons of Canada and was on the faculty of the Department of Medicine of the University of British Columbia. A pioneer in the area of wheelchair sports, Sandy was team doctor at many provincial, national and international sports events, including the Pan Am and Paralympic Games. In 1993, he was awarded the Order of Canada for his many contributions to the people of Canada. He was a keen traveller, an excellent golfer and a lover of good scotch. A man of compassion, he always saw the good in others and will be very much missed by Maisie, his wife of 62 years, his children and his grandchildren.

C Weeks

1016 Ironwork Passage, Vancouver, British Columbia, Canada E-mail: claireweeks@shaw.ca 